\title{
Evaluation of Photosynthetically Available Radiation Algorithm in the Southeastern Brazilian Margin
}

Joao Felipe Cardoso dos Santos and Milton Kampel*

Remote Sensing Division, National Institute for Space Research (INPE), Sao Jose dos Campos, Brazil

*Corresponding author: Milton Kampel, Remote Sensing Division, National Institute for Space Research (INPE), Sao Jose dos Campos, Brazil, Tel: +55 1232086501; E-mail:milton.kampel@inpe.br

Received Date: September 15, 2018; Accepted Date: September 26, 2018; Published Date: October 6, 2018

Copyright: @ 2018 Joao Felipe Cardoso dos Santos, et al. This is an open-access article distributed under the terms of the Creative Commons Attribution License, which permits unrestricted use, distribution, and reproduction in any medium, provided the original author and source are credited.

\begin{abstract}
Photosynthetically available radiation (PAR) comprises the integrated irradiance between $400-700 \mathrm{~nm}$ which reaches the sea surface. Its importance in the marine environment is directly related to primary productivity, which uses light in the atmospheric carbon assimilation reactions. The algorithm for estimating PAR with SeaWiFS, MODIS and MERIS data was evaluated in relation to in situ measurements during the summer and winter of 2001 and 2002. Statistical analyses indicated a systematic error with all three sensors estimates overestimating the in situ measurements with a bias equal to $1.63,1.53$ and 1.64 Einstein $\mathrm{m}^{-2} \mathrm{~d}^{-1}$ and a percentage error equal to $3.95 \%$, $4.13 \%$ and $4.54 \%$, respectively for SeaWiFS, MODIS and MERIS. A Generalized Linear Model (GLM) was adjusted for all sensors decreasing bias and percentage error to values close to zero. The best performance after adjusting was observed with MODIS data followed by SeaWiFS and MERIS, consecutively. Overall, the satellite estimations of PAR showed a good correlation with the in situ measurements and the linear adjustments corrected the observed systematic error.
\end{abstract}

Keywords: Sea surface irradiance; SeaWiFS; MODIS; MERIS; Generalized linear model

\section{Introduction}

The monitoring of photosynthetically available radiation (PAR) in the oceanic environment is relevant for meteo-oceanographic processes such as heat fluxes within the surface layer [1]. Diurnal sea surface temperature (SST) variability [2] and the mixed-layer deepening/shoaling [1]. Biologically, PAR regulates phytoplankton distribution in the water column considering the availability of light energy at different depths [3]. Estimation of daily PAR (Einstein $\mathrm{m}^{-2}$ $\mathrm{d}^{-1}$ ) from ocean colour remote sensing (OCRS) is also important for monitoring the oceanic primary productivity (PP) and the subsequent assimilation of carbon by phytoplankton in the photosynthesis process [4]. Accurate estimation of daily PAR from satellite observations is therefore a prerequisite to provide a global coverage of physical and biogeochemical parameters [4,5].

The assessment of PAR algorithms from different sensors and atmospheric conditions requires comprehensive efforts of validation by in situ measurements [6-12]. Satellite estimates of daily PAR has also been evaluated in PP exercises [13-17]. Although PAR applications are considered relevant in meteo-oceanographic studies and primary productivity exercises, orbital data assessments against observational data measurements in the Southwestern South Atlantic are still scarce in the literature [15] especially in Brazilian waters, which makes it difficult to evaluate the spatiotemporal variability of incoming PAR and its dependence on forcing factors.

The present study aims to evaluate OCRS PAR estimates in the southeastern Brazilian continental margin, located at the Southwestern South Atlantic continental margin, with sensors which have a sufficient set of spectral bands, such as Sea-viewing Wide Field-of-view Sensor (SeaWiFS), MODerate Imaging Spectroradiometer onboard on Aqua satellite (MODIS) and MEdium Resolution Imaging Spectrometer (MERIS). All those sensors were operational during the periods of in situ data acquisition. An empirical regional model was adjusted with in situ data collected in summer and winter of 2001 and 2002 in the study region.

\section{Methodology}

\section{In situ PAR data}

In situ sampling was conducted during 4 mesoscale cruises in austral summer and winter of 2001-2002 in a region located at the northern portion of the Brazilian Southeastern continental margin delimited between Cape of São Tomé (ST), in Rio de Janeiro state $\left(22^{\circ} \mathrm{S}\right)$, and São Sebastião Island (SSI) in São Paulo state $\left(24^{\circ} \mathrm{S}\right)$, Southwestern South Atlantic (Figure la and 1b). PAR data were acquired with a quantum scalar surface reference sensor QSR-240 (Biospherical Instruments Inc.). A spectral irradiance model as described by [18] was also used to determine the available energy in the sea surface, validated with the in situ measurements. The total irradiance (Watt $\mathrm{m}^{-2}$ ) was calculated as a function of time ( $\mathrm{t}$, hours), geographic position (latitude) according to the in situ station coordinates, cloud cover observations during the cruises, day length (hours) and day of the year (Julian calendar). Some adjustments were applied for seasonal variations as suggested by [19].

\section{Satellite PAR data}

Level 1 SeaWiFS daily images were acquired during the austral summer and winter cruises of 2001 and 2002. As MERIS and MODIS onboard satellite Aqua data are only available starting from May and July of 2002, respectively, concomitant daily PAR was acquired only for the winter cruise of 2002. The images for the three sensors were obtained from the OceanColor Web page (https:// 
Page 2 of 5

oceancolor.gsfc.nasa.gov/) supported by the Ocean Biology Processing Group (OBPG) at NASA's Goddard Space Flight Center. The images were processed to Level 2 daily PAR product according this algorithm was first applied to SeaWifs $[20,21]$ and currently is also used on MODIS and MERIS (among other sensors).

OCRS estimation of PAR (Einstein $\mathrm{m}^{-2} \mathrm{~d}^{-1}$ ) is derived from the solar irradiance $\left(\mathrm{E}_{\mathrm{s}}, \mathrm{mW} \mathrm{cm}^{-2} \mu \mathrm{m}^{-1}\right)$ integrated in the visible range of the electromagnetic radiation $(400-700 \mathrm{~nm})$ over the day length defined by latitude and date of acquisition [21]. The implementation of this algorithm (Equation (1)) depends on the availability of the irradiance at the top of the atmosphere limited by saturation clouds:

$$
\operatorname{PAR}(400-700)=\int_{\lambda=400}^{\lambda=700} E_{d}(\lambda) d \lambda=\frac{E_{S}(1-A)}{\left(1-A_{S}\right)\left(1-S_{a} A\right)}
$$

Wher $E_{d}(\lambda)\left(\mathrm{mW} \mathrm{cm}^{-2} \mu \mathrm{m}^{-1}\right)$ is the downward irradiance after the interaction with the atmosphere, $\mathrm{S}_{a}$ refers to the spherical albedo, $\mathrm{A}$ is the albedo of clouds and aerosols on cloud-surface path and can be reduced to $\mathrm{S}_{a}$ when in ideal weather conditions. $\mathrm{E}_{\mathrm{S}}$ is the solar irradiance that should reach the sea surface if A did not exist [22]. At the end of the process, the PAR is obtained in units of $\mathrm{mW} \mathrm{cm}^{-2} \mu \mathrm{m}^{-1}$ and converted to Einstein $\mathrm{m}^{-2} \mathrm{~d}^{-1}$ by a factor of 1.193 with a small percentage of error regardless of weather conditions [23]. The atmospheric correction algorithm is described in Ref. [24] based on [25] according to Equation (2):

$$
\mathrm{L}_{\mathrm{t}}=\left[\mathrm{L}_{\mathrm{r}}+\mathrm{L}_{\mathrm{a}}+\mathrm{t}_{\mathrm{dv}}+\mathrm{L}_{\mathrm{wc}}+\mathrm{t}_{\mathrm{dv}}+\mathrm{L}_{\mathrm{w}}\right] \mathrm{t}_{\mathrm{gv}} \mathrm{t}_{\mathrm{gs}} \mathrm{f}_{\mathrm{p}}
$$

Where $L_{t}$ is the total upwelling radiance observed by the satellite sensor after the interaction with the ocean and atmosphere $L_{r}$ is the contribution from the Rayleigh molecular scattering $\mathrm{L}_{\mathrm{a}}$ is the aerosol contribution $\mathrm{L}_{\mathrm{wc}}$ is the contribution by whitecaps and foam above the sea surface and $\mathrm{L}_{\mathrm{w}}$ is the water-leaving radiance. The radiance $\mathrm{L}$ is spectral resolved and has units of $\mathrm{W} \mathrm{m}^{-2} \mathrm{~nm}^{-1} \mathrm{sr}^{-1}$. The term is the transmittance from diffuse radiation along the ocean to sensor trajectory $\mathrm{t}_{\mathrm{gv}}$ and $\mathrm{t}_{\mathrm{gs}}$ are the transmittance by atmospheric gases in the viewing sensor direction and in the Sun's direction. Finally $f_{p}$ is a polarization-adjustment factor. Both daily PAR and atmospheric correction algorithms were applied to the L1 satellite images following the NASA OBPG descriptions using the SeaWiFS Data Analysis System (SeaDAS) version 7.3.

Level 2 images were reprojected to the geographic coordinate system Datum World Geodetic System 1984 (WGS84), preserving the nominal spatial resolution of $1 \mathrm{~km}$ at nadir for the whole scene using the nearest neighbour algorithm. When two or more images of the same sensor on the same day were available, an average composite was calculated for overlaid pixels. The study area was defined in terms of latitudes $20^{\circ} \mathrm{S}-26^{\circ} \mathrm{S}$ and longitudes $40^{\circ} \mathrm{W}-46^{\circ} \mathrm{W}$ (Figure $1 \mathrm{~b}$ ).

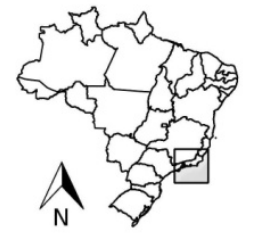

- Summer 2001

$\times$ Winter 2001

- Summer 2002

+ Winter 2002
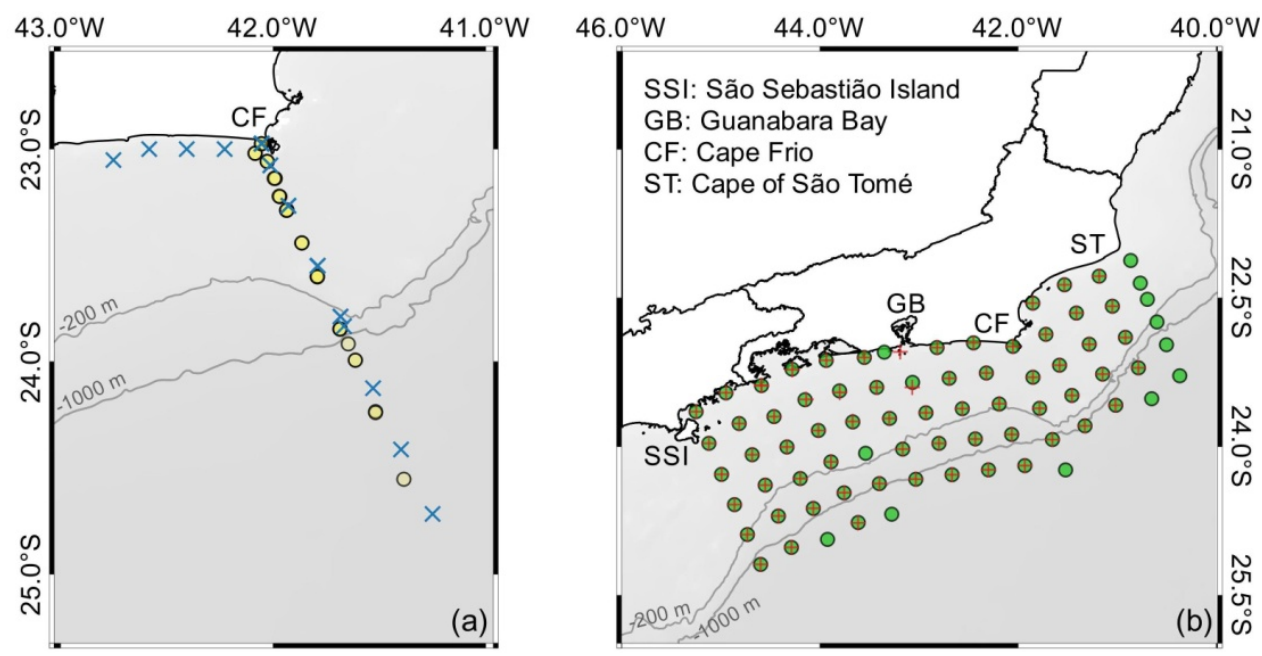

Figure 1: Study area located in the northern portion of the Brazilian Southeastern continental margin, Southwestern South Atlantic. (a) In situ stations of 2001 summer and winter cruises, and (b) the same for 2002 cruises.

\section{Statistical analysis}

Algorithm performance was assessed based on the root mean square error (RMSE), the average error (bias), the percentage error $\%_{\text {error }}$ and the coefficient of determination $\left(\mathrm{r}^{2}\right)$. The criteria to determine the best relative performance is based on the RMSE, bias, $\%_{\text {error }}$ and $\mathrm{r}^{2}$, in this sequence, as suggested by [26]. A box plot chart where values below $\left\{Q_{1}-1.5 \times\left(Q_{3}-Q_{1}\right)\right\}$ and above $\left\{Q_{3}+1.5 \times\left(Q_{3}-Q_{1}\right)\right\}$ where $Q_{1}$ and $Q_{3}$ are the first and third quartiles, respectively, are identified a priori as outliers. Outliers were checked by visual interpretation of the corresponding satellite image confirming or not a possible pixel flag, and then removed previously to statistical analysis.

\section{Results and Discussion}

\section{Algorithm performance assessment}

Overall, PAR derived with SeaWiFS, MODIS and MERIS data slightly overestimates the in situ measurements (Figure 2a-2c). The best performance was obtained for SeaWiFS PAR with RMSE $=1.77$ Einstein $\mathrm{m}^{-2} \mathrm{~d}^{-1}$, bias=1.63 Einstein $\mathrm{m}^{-2} \mathrm{~d}^{-1}$ that corresponds to a 
Citation: Kampel M, Santos JFC (2018) Evaluation of Photosynthetically Available Radiation Algorithm in the Southeastern Brazilian Margin. J

Page 3 of 5

$\%_{\text {error }}=3.95 \%$ higher than the measured values and $\mathrm{r}^{2} \approx 1.0$ (Figure 2(a)). Sequentially, the PAR estimates with MODIS data (Figure 2(b)) were statistically better than with MERIS data (Figure 2(c)). Scatterplots of each satellite PAR against in situ observations reinforced the statistics (Figure 2a-2c).

Main sources of uncertainties are related to cloud cover, time differences between satellite overpass and in situ sampling, and absorption throughout the optical path Frouin et al. [9]. compared SeaWiFS and MODIS PAR values with in situ observations measured at a stationary site off Chesapeake Bay in the North Atlantic. Results were presented as daily, weekly, and monthly uncertainties averaged between 2005 and 2010, also showing an overestimation for SeaWiFS(MODIS) daily PAR RMSE=6.49(6.77) Einstein $\mathrm{m}^{-2} \mathrm{~d}^{-1}$, bias $=$ 2.83(1.85) Einstein $\mathrm{m}^{-2} \mathrm{~d}^{-1}$ and $\mathrm{r}^{2}=0.87(0.86)$. Their result corroborates with the performance observed in the present study before the GLM adjustment.

SeaWiFS PAR product has a disadvantage which is the lack of diurnal variability in clouds, due to the use of a single sensor in a nearnoon orbit [27]. For completely clear sky situations, the PAR estimates derived from satellite data are in much better agreement with the measurements. Another input error of about 1 Einstein $\mathrm{m}^{-2} \mathrm{~d}^{-1}(2$ to $3 \%)$ is attributed to the accuracy of the irradiance model used in conjunction with the field measurement [9]. There was a small seasonal variation in the ratio of satellite-derived and measured PAR values. [21] analysed SeaWiFS PAR estimates in relation to measurements from two moored buoys, one at the relatively high latitude of British Columbia (Halibut Bank, $49^{\circ} \mathrm{N}$ ) and the other in the Equatorial Pacific $\left(0^{\circ} \mathrm{N}\right)$. The authors observed a RMSE equal to 6.2 Einstein $\mathrm{m}^{-2} \mathrm{~d}^{-1}$ for both sites and a lower bias in Halibut (0.93) than in the Pacific (2.9 Einstein $\mathrm{m}^{-2} \mathrm{~d}^{-1}$ ).

A wide range of $\%$ error $(5 \%$ to $73 \%$ )was observed by Vazyula et al. [11] when comparing MODIS PAR with in situ measurements taken taken during a scientific cruise from the Baltic to the White Sea from the end of July to the beginning of August 2014. Lalibert et al. [10] evaluated MODIS PAR Level-3 processing at high northern latitudes and obtained a $\%$ error between $17 \%$ and $20 \%$. In the present study, the $\%_{\text {error }}$ of satellite daily PAR estimates was $\leq 4.54 \%$ which is considered satisfactory for modelling oceanic PP with an accuracy higher than 90\% [28]. However, the performance statistics show a systematic tendency of overestimation that may impact some PP models estimates up to $29 \%[13,14]$.

\section{Adjustment of a generalized linear model (GLM)}

Considering the observed systematic difference, a Generalized Linear Model was adjusted to all three sensors individually, according to Equations (3)-(5):

Sea WiFSPAR ${ }^{*}=0.99[$ SeaWiFS PAR]-1.32 (3)

MODIS PAR ${ }^{*}=0.97[$ MODIS] -0.37 (4)

MERIS PAR ${ }^{*}=0.32[$ MERIS PAR] $+24.21(5)$

Where $\operatorname{PAR}^{*}$ is the adjusted value for each specific sensor; the first term on right is the slope and the second term is the offset Frouin et al. [9]. Inferred that the PAR values may be corrected (reduced) by a factor of 1.02 and 1.03 Einstein $\mathrm{m}^{-2} \mathrm{~d}^{-1}$ for SeaWiFS and MODIS PAR since PAR was computed as the product of the clear sky value. In the present study we found a reduction of 1.32 and 0.37 Einstein $\mathrm{m}^{-2} \mathrm{~d}^{-1}$ for SeaWiFS and MODIS PAR, respectively. With the adjusted GLM, SeaWiFS, MODIS and MERIS PAR ${ }^{*}$ RMSE values decreased to 0.68 , 0.34 , and 1.61 Einstein $\mathrm{m}^{-2} \mathrm{~d}^{-1}$ respectively, while bias decreased to close zero values for all sensors (Figure 2d-2f). After GLM adjustment, the best performance was obtained with MODIS PAR $^{*}$ followed by SeaWiFS PAR ${ }^{*}$ and MERIS PAR ${ }^{*}$. The relatively better performance obtained with MODIS PAR ${ }^{*}$ in relation to SeaWiFS PAR $^{*}$ can be associated to less cloudiness during the winter in response to precipitation variability characterized by a rainy summer in the region [29]. Also, typical lower sea surface temperature values during winter may reduce the evaporation and consequently the formation of clouds during the day resulting in better estimates from OCRS. 

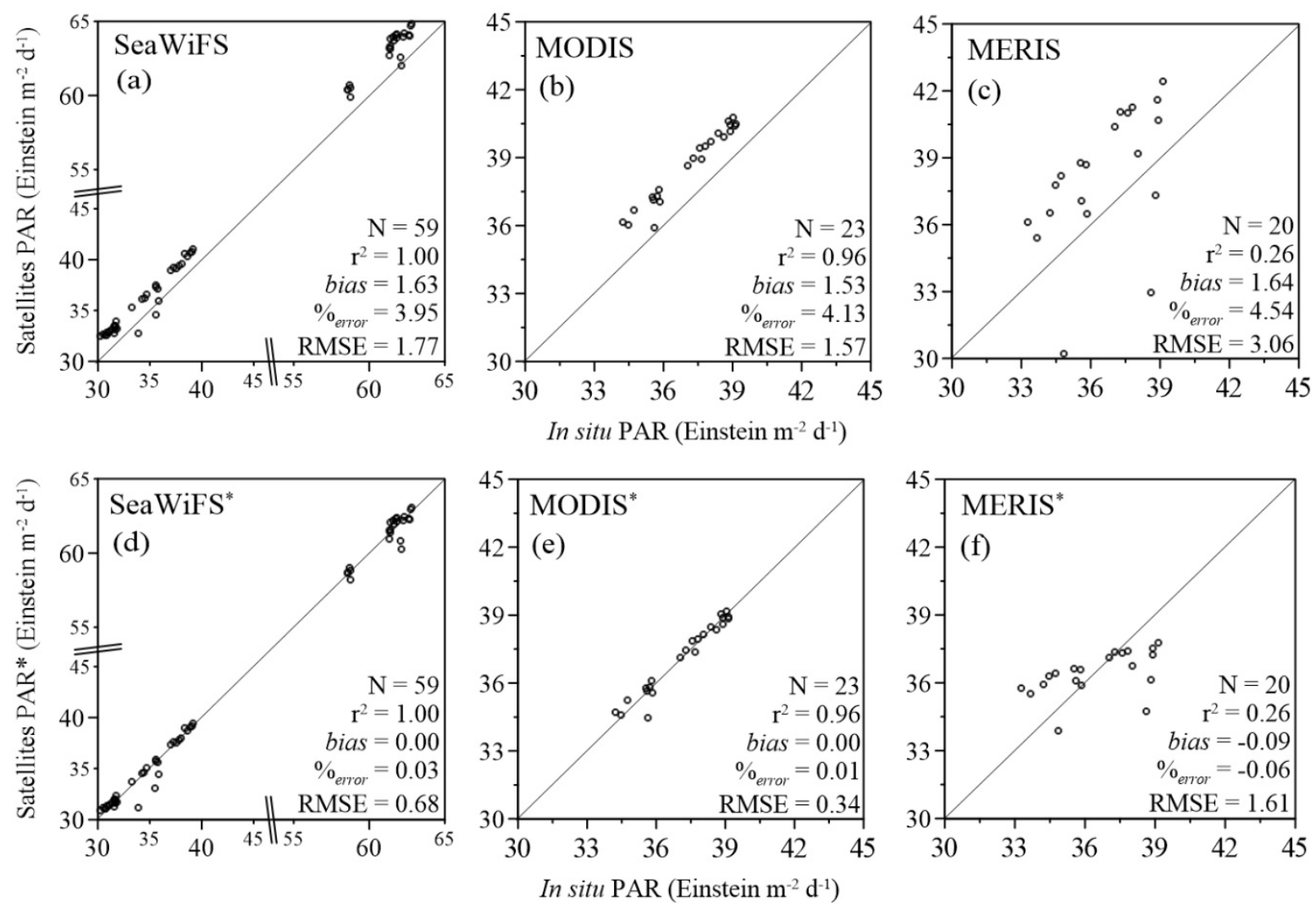

Figure 2: Scatter plots of in situ measured daily PAR against non-adjusted PAR (a, b, c) and GLM adjusted PAR (d, e, f) from SeaWiFS, MODIS and MERIS estimates.

Dogliotti et al. [15] observed a bias equal to 10 Einstein $\mathrm{m}^{-2}$
$\mathrm{~d}^{-1}(\%$ error $\sim 48 \%)$ with MODIS PAR in the Argentine shelf $\left(39^{\circ} \mathrm{S}\right.$ to
$\left.55^{\circ} \mathrm{S}\right)$ and adjacent region during austral spring, late summer and late
winter seasons. According to those authors the PAR estimation had a
good $\mathrm{r} 2$ in relation with in situ measurements explaining $~ 70 \%$ of
variance $(\mathrm{N}=36)$ suggesting that a GLM adjustment should be applied.

Accuracy of heliosynchronous satellite daily PAR products is limited by the absence of information about diurnal variability of clouds [9]. Hourly observations can be obtained from geostationary satellites [30] and integrated over time to provide daily values Qi et al. [5]. compared PAR estimates from MODIS and Geostationary Operational Environmental Satellite system (GOES) in the Gulf of Mexico region for the entire year of 2013. According to the authors, MODIS daily PAR tends to be lower than GOES PAR suggesting that when MODIS PAR is used in estimating PP, PP may be underestimated.

Ramon et al. [17] developed a MERIS PAR algorithm based on the NASA OBPG operational algorithm [21] accounting for a diurnal variability of clouds. The daily MERIS PAR estimates were compared with in situ measurements acquired at four sites located at midlatitudes: BOUSSOLE buoy in the Mediterranean Sea (2009-2015), CCE1 and CCE2 moorings off the California coast (2008-2015 and 2011-2015, respectively) and COVE off the East cost of United States (2003-2014). The RMSE error was 8.10 ( $_{\text {error }}=23.74 \%$ ) Einstein $\mathrm{m}^{-2} \mathrm{~d}^{-1}$ without statistical correction of diurnal cloud variability and $8.5(\%$ error $=24.90 \%)$ Einstein $\mathrm{m}^{-2} \mathrm{~d}^{-1} \quad$ with cloud correction. The bias was reduced from 3.27 Einstein $\mathrm{m}^{-2} \mathrm{~d}^{-1}(\%$ error $=9.57 \%)$ without cloud correction to 2.65 Einstein $\mathrm{m}^{-2} \mathrm{~d}^{-1}$ ( $\%_{\text {error }}=7.77 \%$ ) with cloud correction. In both cases, $\mathrm{r}^{2}$ values were $>0.80$ suggesting that an adjustment of a GLM could practically approach to zero value the systematic overestimation.

\section{Conclusion}

Comparisons of SeaWiFS, MODIS and MERIS PAR estimates with in situ measurements show agreement, with more than $90 \%$ of accuracy. However, all three satellite estimates were biased, by about $3.95 \%$ (SeaWIFS), $4.13 \%$ (MODIS) and $4.54 \%$ (MERIS). The overestimation may be due to combined effects of cloud cover, atmospheric corrections, satellite's overpass time and sensor characteristics. A generalized linear model was adjusted regionally correcting the observed systematic differences. The regionally adjusted GLM effectively improved the estimation of PAR derived with SeaWiFS, MODIS and MERIS data. MERIS PAR still requires an additional effort for better tuning which could be worthwhile given that Ocean Land Colour Instrument (OLCI) has been designed with similar specifications with addition of six extra spectral bands. In this way PAR estimates derived from other ocean colour sensors currently in operation such as the Visible Infrared Imaging Radiometer Suite (VIIRS) should also be validated in the study region. The combination of geostationary and polar orbit satellites may allow retrieving information about daily atmospheric/clouds variability decreasing the 
uncertainties still present in current PAR algorithms and models. Important to note that the comparative analyses has been made using a relatively limited data set, which is insufficient to derive definite conclusions about accuracy. Additional imagery and in situ measurements needs to be analysed, considering different atmospheric conditions and seasons. At present, an effort is being made to bring together a longer time series of data acquired in the study region as part of the ANTARES Latin-American network (www.antares.ws). The assessment of PAR products is part of a larger effort to define the best input algorithms and products to be applied in regional primary productivity models.

These results showed that the GLM was a good choice to correct the systematic deviation present on estimates with the three sensors and that a simple linear model was able to improve the PAR estimate regionally.

\section{Acknowledgement}

DEPROAS project was funded by CNPq/PRONEX-FINEP Brazilian Government. The present study was partially funded by the InterAmerican Institute for Global Changes Research (IAI/US-NSF GEO-1128040 grant) and National Council for Scientific and Technological Development (CNPq, 132971/2014-3). The authors would like to thank the Ocean Biology Processing Group (OBPG) for SeaDAS and OCRS data distribution.

\section{References}

1. Kawai Y, Wada A (2007) Diurnal sea surface temperature variation and its impact on the atmosphere and ocean: a review. J Oceanogr 63: 721-44.

2. Gentemann CL, Donlon CJ, Stuart-Menteth A, Wentz FJ (2003) Diurnal signals in satellite sea surface temperature measurements. Geophys. Res Lett 30: 1140.

3. Sigman DM, Hain MP (2012) The biological productivity of the ocean. Nature education 3: 21.

4. Harmel T, Chami M (2016) Estimation of daily photosynthetically active radiation (PAR) in presence of low to high aerosol loads: application to OLCI-like satellite data. Optics Express 24 :A1390-1407.

5. Qi L, Lee Z (2016) Comparison between photosynthetically available radiation (PAR) estimated from MODIS and GOES over the Gulf of Mexico. Proceedings of the IEEE 5845-47.

6. Frouin R, Murakami H (2007) Estimating photosynthetically available radiation at the Ocean Surface from ADEOS-II global imager data. J Oceanogr 63: 493-503.

7. Liu R, Liang S, He H, Liu J, Zheng $\mathrm{T}$ (2008) Mapping incident photosynthetically active radiation from MODIS data over China Remote Sens. Environ., 112: 998-1009.

8. Wu G, Leeuw J, Skidmore AK, Yaolin L, Prins HHT (2010) Comparison of extrapolation and interpolation methods for estimating daily photosynthetically active radiation (PAR). Geo-spatial Information Science, 13: 235-242.

9. Frouin R, McPherson J, Ueyoshi K, Franz BA (2012) A time series of photosynthetically available radiation at the ocean surface from SeaWiFS and MODIS data. Proceedings of SPIE, Japan.

10. Laliberté J, Bélanger S, Frouin R (2016) Evaluation of satellite-based algorithms to estimate photosynthetically available radiation (PAR) reaching the ocean surface at high northern latitudes. Remote Sens. Environ 184: 199-211.
11. Vazyulya SV, Kopelevich OV, Sheberstov SV, Artemiev VA (2016) Estimation of sea surface solar radiation at $400-700 \mathrm{~nm}$ using satellite ocean color data, and its validation by ship data. Optics Express 24: A604A611.

12. Wenjun T, Jun Q, Kun Y, Xiaolei N, Min M, et al. (2017) An efficient algorithm for calculating photosynthrtically active radiation with MODIS products. Remote Sens. Environ 194:146-154.

13. Friedrichs MAM, Carr M, Barber RT, Scardi M, Antoine D, et al. (2009) Assessing the uncertainties of model estimates of primary productivity in the tropical Pacific ocean. J Marine Syst 76: 113-133.

14. Saba VS, Friedrichs MAM, Antoine D, Armstrong RA, Asanuma I, et al. (2011) An evaluation of ocean color model estimates of marine primary productivity in coastal and pelagic regions across the globe. Biogeosciences 8: 489-503.

15. Dogliotti AI, Lutz VA, Segura V (2014) Estimation of primary production in the southern argentine continental shelf and shelf-break regions using field and remote sensing data. Remote Sens. Environ 140: 497-508.

16. Tripathy M, Raman M, Chauhan P, Ajai (2014) Modulation in Ocean Primary Production due to variability of photosynthetically available radiation under different atmospheric conditions. Int J Oceangr 10: pp12.

17. Ramon D, Jolivet D, Tan J, Frouin R (2016) Estimating photosynthetically available radiation at the ocean surface for primary production (3P Project): modeling, evaluation, and application to global MERIS imagery. Proceedings of SPIE 9878.

18. Bird R.E (1984) A simple solar spectral model for direct-normal diffuse horizontal irradiance. Solar Energy 32: 461-471.

19. Sathyendranath S. Platt T (1988) The spectral irradiance field at the surface and in the interior of the Ocean: a model for applications in Oceanography and Remote Sensing. J Geoph Res 93: 9270-80.

20. Frouin R, Chertock B (1992) A technique for global monitoring of net solar irradiance at the ocean surface Part I: Model. J Appl Meteor 31: 1056-66.

21. Frouin R, Franz BA, Werdell PJ (2003) The SeaWiFS PAR product. In: S.B. Hooker and E.R. Firestone (ed), Algorithm Updates for the Fourth SeaWiFS Data Reprocessing, NASA Tech Memo, NASA Goddard Space Flight Center, Greenbelt, Maryland.

22. Zege EP, Ivaniv AP, Katsev IL (1991) Image transfer through a scattering medium. Springer-Verlag.

23. Kirk JTO (2011) Light and photosynthesis in aquatic ecosystems. (3rd ed), Cambridge University Press.

24. Mobley CD, Werdell J, Franz B, Ahmad Z, Bailey S (2016) Atmospheric correction for satellite ocean color radiometry. A tutorial and documentation NASA ocean biology processing group 1-73.

25. Franz B, Bailey SW, Werdell PJ, McClain CR (2007) Sensor-independent approach to the vicarious calibration of satellite ocean color radiometry. Appl Optics 46: 5068-82.

26. IOCCG (2007) Ocean-colour data merging. Reports of the International Ocean Colour Coordinating Group 6: 74.

27. Gregg WW, Casey NW (2009) Skill assessment of a spectral oceanatmosphere radiative model. J Marine Syst 76: 49-63.

28. Frouin R, Pinker RT (1995) Estimating photosynthetically active radiation (PAR) at the earth's surface from satellite observations. Remote Sens. Environ 51: 98-107.

29. Frouin R, McPherson J (2012) Estimating photosynthetically available radiation at the ocean surface from GOCI data. Ocean Sci J 47: 313-21.

30. Sant’Anna Neto JL (2005) Decálogo da climatologia do sudeste brasileiro. Revista Brasileira de Climatologia, 1: 43-60. 